\title{
Efeito da combinação de espécies de fungos entomopatogênicos e de temperatura de incubação na mortalidade de Alphitobius diaperinus Panzer (Coleoptera: Tenebrionidae)
}

\author{
Effect of combinations of entomopathogenic fungi species and \\ incubation temperatures on the mortality of Alphitobius diaperinus \\ Panzer (Coleoptera: Tenebrionidae)
}

\author{
Juliana Cristina dos Santos ${ }^{1,3}$; Luis Francisco Angeli Alves ${ }^{1 *}$; \\ Andréia Kusumota Bonini ${ }^{1}$; Cristhiane Rohde ${ }^{2}$
}

\begin{abstract}
Resumo
O objetivo deste trabalho foi avaliar, em condições de laboratório, o efeito dos fungos entomopatogênicos Beauveria bassiana e Metarhizium anisopliae isoladamente e em mistura com diferentes concentrações, e em duas temperaturas de incubação, contra larvas e adultos do cascudinho dos aviários (A. diaperinus). Os insetos foram imersos por 10 segundos sob agitação, em suspensões de conídios de ambos os fungos, em diferentes percentuais de B. bassiana e M. anisopliae nas seguintes combinações $100: 0 ; 25$ $: 75 ; 50: 50 ; 75: 25$; testemunha, contendo no máximo $1 \times 10^{8}$ conídios $/ \mathrm{mL}$. Em seguida, foram incubados a $26 \mathrm{e} 32^{\circ} \mathrm{C}$ e fotofase de 14 horas, sendo preparadas quatro repetições de 15 insetos para cada tratamento, tanto para larvas como para adultos, respectivamente. A mortalidade foi avaliada diariamente, sendo os insetos mortos desinfectados em álcool 70\% e mantidos em câmara úmida nas mesmas condições descritas, para confirmação da morte pelos fungos. Na temperatura de $26^{\circ} \mathrm{C}$, verificou-se que na mistura de fungos somente houve mortalidade confirmada por $B$. bassiana e não houve diferença na mortalidade larval causada por este fungo, em mistura ou isoladamente. Em relação aos adultos, no tratamento de mistura de fungos houve redução na mortalidade em relação ao fungo isoladamente. $\mathrm{Na}$ temperatura de $32^{\circ} \mathrm{C}$ a mistura elevou a ação de B. bassiana contra larvas em duas combinações ( $50 \%$ de cada fungo e $75 \%$ de B. bassiana $+25 \%$ de $M$. anisopliae), mas reduziu em todas as combinações contra adultos. Houve também efeito negativo da temperatura sobre os fungos, que foram mais efetivos sobre as larvas a $26^{\circ} \mathrm{C}$. Palavras-chave: Controle biológico, Beauveria bassiana, Metarhizium anisopliae, produção animal
\end{abstract}

\footnotetext{
1 Universidade Estadual do Oeste do Paraná, Centro de Ciências Biológicas e da Saúde, Laboratório de Zoologia de Invertebrados. E-mail:1faalves@unioeste.br

2 Programa de Mestrado em Entomologia, Universidade Federal de Lavras, Departamento de Entomologia

3 Bolsista de Produtividade em Pesquisa, CNPq.

* Autor para correspondência
} 


\begin{abstract}
The objective of this work was to evaluate the effect of the entomopathogenic fungi Beauveria bassiana and Metarhizium anisopliae under laboratory conditions, either individually or mixed at different concentrations, and at two incubation temperatures, against larvae and adults of the lesser mealworm ( $A$. diaperinus). The insects were immersed in conidial suspensions at different rates of both fungi (respectively to $B$. bassiana and M. anisopliae $100: 0 ; 25: 75 ; 50: 50 ; 75: 25$; control), containing a maximum of $1 \times 10^{8}$ conidia $/ \mathrm{mL}$, for 10 seconds under agitation. They were then incubated at 26 or $32^{\circ} \mathrm{C}$, and a 14-hour photophase. Four replicates of 15 insects were prepared for each treatment, containing either larvae or adults, respectively. Mortality was evaluated daily. Dead insects were disinfected in $70 \%$ alcohol and maintained in a humid chamber under the same conditions described above, to confirm death by the fungi. It was verified that confirmed mortality in the mixture was caused only by B. bassiana. When mixed, the action of the fungus at $26^{\circ} \mathrm{C}$ did not increase significatively against larvae, and decreased against adults. At $32^{\circ} \mathrm{C}$, the mixture increased the action of $B$. bassiana against larvae in two of the combinations ( $50 \%$ of each fungus and $75 \%$ B. bassiana $+25 \%$ M. anisopliae), but decreased in all combinations against adults. There was also a negative effect of temperature on the fungi, which were more effective against larvae at $26^{\circ} \mathrm{C}$.
\end{abstract}

Keywords: Biological control, Beauveria bassiana, Metarhizium anisopliae, animal production

\section{Introdução}

Os atuais sistemas de criação e manejo de aves de corte favorecem a ocorrência do cascudinho (Alphitobius diaperinus (Panzer), que apesar de ser um inseto considerado praga secundária de grãos armazenados, adaptou-se às condições do aviário, passando a infestar o ambiente, concentrando-se na cama das aves. Nela, o inseto encontra abundância de alimento (resíduos orgânicos, cadáveres e ração), abrigo e temperatura adequada para sua reprodução, alcançando altas populações (DESPINS; TURNER; RUSZLER, 1989; CHERNAKI-LEFFER et al., 2001).

Dentre os problemas associados à presença do cascudinho nos aviários, destacam-se sua ingestão pelas aves no lugar da ração balanceada, com redução no crescimento e ganho de peso pelas aves, além de serem comprovadamente hospedeiros e/ou transmissores de microrganismos patogênicos às aves, como fungos (Aspergillus), bactérias (Salmonella spp., Echerichia coli, Proteus mirabilis, $P$. vulgaris e Enterobacter agglomerans), vírus (influenza, rotavírus, enterovírus) e protozoários (coccidiose e leucose) (AXTELL; ARENDS, 1990; AVANCINI; UETA,
1990; MCALLISTER et al., 1995; CHERNAKILEFFER et al., 2002).

Atualmente, o controle deste inseto é realizado, com baixa eficiência, utilizando-se inseticidas organofosforados e piretróides. Neste contexto, buscam-se alternativas e estratégias para o controle da praga, com uso de nematóides e fungos entomopatogênicos (GEDEN; AXTELL; BROS, 1985; PEZOWICZ, 2003; ALVES; ROHDE; ALVES, 2005).

Os fungos entomopatogênicos Beauveria bassiana e Metarhizium anisopliae têm sido observados em ocorrências naturais em aviários, nos EUA e no Brasil (STEINKRAUS; GENDEN; RUTZ, 1991; ALVES et al., 2004; ALVES; ROHDE; ALVES, 2005), sendo que as condições internas do aviário (temperatura e umidade constantes, populações elevadas da praga e abrigo da luz solar), conforme Alves e Lecuona (1998), são favoráveis ao estabelecimento e disseminação do fungo no ambiente. Além disso, a patogenicidade de tais fungos foi comprovada experimentalmente contra larvas e adultos do cascudinho, sendo obtidos resultados animadores, principalmente contra larvas (CRAWFORD; BROOKS; ARENDS, 1998; GEDEN et al., 1998; ROHDE et al., 2006). 
Além disso, na temperatura de $32^{\circ} \mathrm{C}$ o fungo $M$. anisopliae mostrou-se mais eficiente contra larvas, em relação ao fungo $B$. bassiana sendo observados 68 e $28 \%$ de mortalidade, respectivamente, sugerindo a possibilidade de integrar ambos os fungos no controle do inseto no aviário, visto que a cama do aviário apresenta variação térmica na faixa de 25 a $35^{\circ} \mathrm{C}$, favorecendo o desenvolvimento do fungo (ALVES et al., 2004; ALEXANDRE et al., 2006).

Tais observações concordam com Alves e Lecuona (1998), que afirmam que os isolados de $M$. anisopliae toleram uma faixa mais ampla de temperaturas (entre 24 e $32^{\circ} \mathrm{C}$ ) para seu desenvolvimento, enquanto os isolados de $B$. bassiana toleram uma faixa de temperatura mais restrita (entre 22 e $26^{\circ} \mathrm{C}$ ).

A combinação de diferentes isolados ou espécies de entomopatógenos é algo pouco explorado, principalmente em relação aos fungos. Contudo, há relatos para interações de nematóides e Bacillus thuringiensis, que indicam efeitos sinérgicos, aditivos ou antagônicos, dependendo das circunstâncias do experimento, não permitindo qualquer tipo de generalização (KAIA et al., 1995)

Também, diferentes combinações de $B$. bassiana, B. brongniartii e vírus (VGDs) aplicados em lagartas de Diatraea saccharalis (Fabricius), sob várias temperaturas de incubação levou à ocorrência de comportamentos variados, sendo que de modo geral, houve incremento na ação dos fungos (LECUONA; ALVES, 1988).

A avaliação de $B$. bassiana e $M$. flavoviridae, em mistura ou não, avaliados contra gafanhotos (Malanoplus sanguinipes) (Pickford e Randell), e em diferentes temperaturas, evidenciou a ausência de diferença entre os tratamentos quando os insetos foram incubados a $25^{\circ} \mathrm{C}$. Contudo, no caso de oscilações térmicas, quando a temperatura variou acima de $25^{\circ} \mathrm{C}$, houve prevalência de $M$. flavoviridae, sendo o inverso observado em ambiente com temperaturas mais baixas, tanto em aplicações isoladas como em mistura de espécies (INGLIS et al., 1997).

Assim, este trabalho foi realizado com o objetivo de se avaliar "in vitro", o efeito da mistura de conídios de B. bassiana e $M$. anisopliae em diferentes proporções e sob duas temperaturas de incubação, em larvas e adultos de $A$. diaperinus.

\section{Material e Métodos}

Os insetos foram coletados no aviário comercial, na região de Cascavel, $\mathrm{PR}$, sendo mantidos em potes plásticos (50 cm de altura x $17 \mathrm{~cm}$ de diâmetro), em temperatura ambiente $\left(25 \pm 1^{\circ} \mathrm{C}\right)$.

Isolados de Beauveria bassiana (Unioeste 4) e Metarhizium anisopliae (UEL50), previamente selecionados para o controle do cascudinho por Rohde et al. (2006) e provenientes do banco de entomopatógenos da Unioeste, foram multiplicados em meio de esporulação (M.E.) (ALVES et al., 1998) e armazenados em tubos de vidro a $4^{\circ} \mathrm{C}$, até a realização do experimento.

Foram preparadas suspensões de conídios de ambos os fungos, em solução de água destilada + espalhante adesivo Tween $80(0,01 \%)$ e padronizadas na concentração de $1 \times 10^{8}$ conídios $/ \mathrm{mL}$, sendo esta concentração determinada previamente como adequada para avaliação da patogenicidade de fungos contra o cascudinho (ROHDE et al., 2006). Em seguida, foram preparadas misturas de ambos os fungos em diferentes combinações, de forma que a concentração final fosse sempre $1 \times 10^{8}$ conídios $/ \mathrm{mL}$ (Tabela 1). 
Tabela 1. Combinações das diferentes porcentagens de fungos entomopatogênicos B. bassiana (Unioeste 4) e $M$. anisopliae (UEL 50), nas temperaturas de 26 e $32^{\circ} \mathrm{C}$.

\begin{tabular}{lcc}
\hline Tratamentos & \% de fungos utilizados na mistura & Concentração de conídios/mL \\
\hline Testemunha & - & - \\
Unioeste 4 & 100 & $1 \times 10^{8}$ \\
UEL50 : Unioeste 4 & $25: 75$ & $2,5 \times 10^{7}: 7,5 \times 10^{7}$ \\
UEL50 : Unioeste 4 & $50: 50$ & $5 \times 10^{7}: 5 \times 10^{7}$ \\
UEL50 : Unioeste 4 & $75: 25$ & $7,5 \times 10^{7}: 2,5 \times 10^{7}$ \\
UEL50 & 100 & $1 \times 10^{8}$ \\
\hline
\end{tabular}

A inoculação seguiu a metodologia padronizada de seleção de fungos para o controle deste inseto, e constou de copos plásticos de $50 \mathrm{~mL}$ de capacidade contendo alíquotas de $1 \mathrm{~mL}$ das diferentes misturas nas quais foram imersos 15 larvas ou 15 adultos de cascudinho separadamente, sob agitação por 10 segundos. Após a inoculação, as larvas foram individualizadas em caixas acrílicas $(3 \mathrm{~cm}$ de diâmetro) e os adultos em placa de Petri, todas com o fundo recoberto por papel-filtro e alimentados com ração esterilizada para aves e deixados a 26 e $32^{\circ} \mathrm{C}$, com fotoperíodo de 14 horas (ROHDE et al., 2006).

Seguiu-se a mesma metodologia para seleção de fungos para a avaliação da mortalidade, sendo as avaliações realizadas diariamente por um período de 10 dias. Os insetos mortos foram desinfectados em álcool 70\%, e imersos em água destilada estéril por um intervalo de 10 segundos, e então acondicionados em câmara úmida, e incubados em sua respectiva temperatura $\left(26\right.$ ou $\left.32^{\circ} \mathrm{C}\right)$, para confirmação do agente causal da mortalidade.

Adotou-se o delineamento fatorial inteiramente casualizado, com quatro repetições, e os dados de mortalidade confirmada foram transformados em $\operatorname{arcsen} \sqrt{x / 100}$, e submetidos à análise de variância (teste F) e as médias comparadas entre si pelo teste de Tukey a $5 \%$ de significância.

\section{Resultados e Discussão}

Independente da temperatura de incubação houve a ação dos fungos sobre os insetos, com maior mortalidade confirmada na fase larval a $26^{\circ} \mathrm{C}$ e $B$. bassiana foi mais efetivo que $M$. anisopliae quando testados separadamente (83 e 50\% de mortalidade larval) (Tabela 2).

Verificou-se também que nos casos de mistura de espécies, sempre ocorreu a mortalidade confirmada por B. bassiana, a despeito da proporção de conídios utilizada nos tratamentos e da temperatura de incubação.

Observou-se que em todos os tratamentos com mistura de espécies na temperatura de $26^{\circ} \mathrm{C}$, a mortalidade larval não diferiu significativamente do isolado Unioeste4 utilizado isoladamente $(\mathrm{P}<0,05)$.

Em relação à mortalidade de adultos, nos tratamentos com mistura de espécies, a mortalidade foi significativamente menor que no tratamento com $B$. bassiana sozinho. Além disso, não houve mortalidade nesta fase de desenvolvimento provocada pelo fungo $M$. anisopliae utilizado isoladamente.

A menor mortalidade observada para os adultos na mistura de isolados em relação ao $B$. bassiana isoladamente pode ser atribuída à menor suscetibilidade do inseto nesse estágio de desenvolvimento e corroborando com dados de Geden et al. (1998) e Alexandre et al. (2006). 
Tabela 2. Porcentagem de mortalidade confirmada de larvas e adultos de A. diaperinus submetidos a diferentes combinações de conídios de B. bassiana $(\mathrm{Bb})$ e $M$. anisopliae $(\mathrm{Ma})$ nas temperaturas de 26 e $32^{\circ} \mathrm{C}$.

\begin{tabular}{|c|c|c|c|c|}
\hline \multirow{2}{*}{$\begin{array}{c}\text { Espécies de fungo/ } \\
\text { concentração (conídios/mL) }\end{array}$} & \multicolumn{2}{|c|}{$26^{\circ} \mathrm{C}$} & \multicolumn{2}{|r|}{$32^{\circ} \mathrm{C}$} \\
\hline & Larva & Adulto & Larva & Adulto \\
\hline Testemunha & $0,0 \pm 0,0 \mathrm{Ca}$ & $0,0 \pm 0,0 \mathrm{Ca}$ & $0,0 \pm 0,0 \mathrm{Ca}$ & $0,0 \pm 0,0 \mathrm{Ca}$ \\
\hline $\mathrm{Bb}\left(1 \times 10^{8}\right)$ & $83,4 \pm 4,4 \mathrm{Aa}$ & $85,0 \pm 3,8 \mathrm{Aa}$ & $18,3 \pm 2,2 \mathrm{Bb}$ & $18,4 \pm 6,7 \mathrm{Ab}$ \\
\hline $\mathrm{Ma}\left(1 \times 10^{8}\right)$ & $50,0 \pm 8,0 \mathrm{Ba}^{*}$ & $0,0 \pm 0,0 \mathrm{Ca}$ & $11,7 \pm 4,4 \mathrm{Bb}^{* *}$ & $0,0 \pm 0,0 \mathrm{Ca}$ \\
\hline $\mathrm{Bb}\left(5 \times 10^{7}\right): \mathrm{Ma}\left(5 \times 10^{7}\right)$ & $98,3 \pm 0,0 \mathrm{Aa}^{*}$ & $62,7 \pm 2,2 \mathrm{Ba}$ & $28,3 \pm 9,7 \mathrm{Ab}^{* *}$ & $5,0 \pm 0,0 \mathrm{Bb}$ \\
\hline $\mathrm{Bb}\left(7,5 \times 10^{7}\right): \mathrm{Ma}\left(2,5 \times 10^{7}\right)$ & $96,7 \pm 0,0 \mathrm{Aa}^{*}$ & $58,3 \pm 3,8 \mathrm{Ba}$ & $33,3 \pm 14,6 \mathrm{Ab}^{* *}$ & $0,0 \pm 0,0 \mathrm{Cb}$ \\
\hline $\mathrm{Bb}\left(2,5 \times 10^{7}\right): \mathrm{Ma}\left(7,5 \times 10^{7}\right)$ & $81,7 \pm 8,0 \mathrm{Aa}^{*}$ & $56,7 \pm 4,4 \mathrm{Ba}$ & $18,3 \pm 4,4 \mathrm{ABb}^{* *}$ & $1,7 \pm 0,0 \mathrm{Cb}$ \\
\hline
\end{tabular}

Para as análises estatísticas os dados foram transformados em arcsen. $\sqrt{x / 100}$. Médias $( \pm \mathrm{EP})$ seguidas de mesma letra maiúscula na coluna e mesma letra minúscula na linha para o mesmo estágio de desenvolvimento, entre as temperaturas, não diferem entre si, pelo teste de Tukey $(\mathrm{P}<0,05)$

* médias com diferença significativa quanto à suscetibilidade de larvas e adultos incubados a $26^{\circ} \mathrm{C}$

** médias com diferença significativa quanto à suscetibilidade de larvas e adultos incubados a $32^{\circ} \mathrm{C}$

Além disso, os valores aqui obtidos de mortalidade confirmada para os adultos nos tratamentos com os fungos associados (entre 56 e $65 \%$ ) concordam com o estudo comparativo de isolados de B. bassiana para o cascudinho realizado por Rohde et al. (2006), que obtiveram 53,4 e 76\% de mortalidade de adultos, respectivamente para a concentração de $1 \times 10^{7} \mathrm{e}$ $1 \times 10^{8}$ conídios $/ \mathrm{mL}$.

Ressalta-se que a mortalidade baixa obtida com o fungo $M$. anisopliae contrasta com dados obtidos por Chernaki-Leffer (2004), que realizando uma seleção de isolados de fungos para este mesmo inseto, obteve para esse fungo, maiores percentuais de mortalidade em relação aos demais. Contudo, entre ambos os estudos houve variação na técnica de inoculação, sendo tópica no primeiro e por imersão no presente trabalho. Além disso, houve também diferença entre os isolados utilizados, que de acordo com a variabilidade genética dos mesmos, podem ser obtidos resultados variados, como comprovado por Rohde et al. (2006).

$\mathrm{Na}$ temperatura de $32^{\circ} \mathrm{C}$, a eficiência do fungo foi drasticamente reduzida se comparada à outra temperatura, sendo a mortalidade confirmada obtida significativamente menor em todos os tratamentos, tanto para larvas como para adultos $(\mathrm{P}<0,05)$.
Contudo, considerando-se a mortalidade nesta temperatura, verificou-se que os valores obtidos para larvas foram maiores que para os adultos, exceto no tratamento com B. bassiana isoladamente, confirmando os resultados obtidos na menor temperatura, e concordando, em parte, com dados de Alexandre et al. (2006), para esta mesma espécie de fungo.

Em relação ao fungo $M$. anisopliae, assim como observado na temperatura de $26^{\circ} \mathrm{C}$, houve apenas confirmação da mortalidade pelo mesmo somente no tratamento em que foi utilizado isoladamente.

Considerando que a morte do inseto é resultante de uma série de fatores como a presença de toxinas liberadas pelo fungo e alterações morfo-fisiológicas provocadas pela presença e desenvolvimento do fungo no interior do inseto, fatores ambientais, como a temperatura e umidade são importantes para o desenvolvido das etapas da relação fungo-hospedeiro (PEREIRA; ALVES; REIS, 1998).

Tal fato é comprovado por Alexandre et al. (2006), observando que $M$. anisopliae apresentou elevada capacidade de germinação e bom crescimento na temperatura de $26^{\circ} \mathrm{C}$ e que em $32^{\circ} \mathrm{C}$, ainda que a germinação não tenha sido afetada, o seu crescimento 
foi reduzido, porém, maior que o observado para $B$. bassiana na mesma temperatura. $\mathrm{O}$ mesmo é válido em relação à produção de conídios entre ambas as espécies de fungo.

Corroborando tais observações, Lecuona e Alves (1988) verificaram que em $30^{\circ} \mathrm{C}$, a germinação de $B$. bassiana e $B$. brongniartii não foi afetada, ocorrendo normalmente após 24 horas de incubação, sugerindo que a perda de patogenicidade, também constatada por eles, tenha sido resultante da ação negativa da temperatura sobre outras fases do ciclo de infecção, como a penetração ou colonização do hospedeiro.

A confirmação da mortalidade apenas por $B$. bassiana em todos os tratamentos com mistura de espécies indica provável competição entre os fungos. Vale ressaltar, porém, que a $32^{\circ} \mathrm{C}$ a mistura de espécies nas proporções de $75: 25 \%$ (B. bassiana : M. anisopliae) e $50 \%$ de cada (respectivamente 7,5 $\times 10^{7}: 2,5 \times 10^{7}$ e $5 \times 10^{7}: 5 \times 10^{7}$ canídios $/ \mathrm{mL}$ ), evidenciou efeito sinérgico, considerando que houve acréscimo de cerca de 10 a 20\% na mortalidade de larvas em relação ao obtido com os fungos isoladamente, mesmo estando B. bassiana em concentração menor que a do tratamento em que foi aplicado isoladamente.

Contudo, fatores intrínsecos dos fungos baseados em princípios competitivos entre ambos podem ter levado ao crescimento de apenas uma das espécies associadas no tratamento, concordando em partes com o que observaram Garcia et al. (1990), segundo os quais, geralmente as combinações das espécies aqui utilizadas não resultam em ganho na mortalidade sugerindo competição entre as espécies.

Futuros testes em condições de campo poderão confirmar tais observações, evidenciando ainda qual o potencial da mistura para o controle da praga em questão.

\section{Conclusões}

O uso de mistura de espécies de fungo provocou aumento na mortalidade do cascudinho apenas na temperatura de $32^{\circ} \mathrm{C}$, sendo o efeito evidenciado apenas contra larvas do inseto.

\section{Agradecimentos}

À Fundação Araucária pelo auxílio financeiro para o desenvolvimento da pesquisa e aos colegas que colaboraram na revisão prévia do manuscrito.

Ao CNPq pela concessão de bolsa de Produtividade em Pesquisa.

\section{Referências}

ALEXANDRE, T. M.; ALVES, L. F. A.; NEVES, P. M. O.; ALVES, S. B. Efeito da temparatura e substrato sobre Beauveria bassiana e Metarhizium anisopliae e sua relação no controle do cascudinho (Alphitobius diaperinus) (Panzer) (Coleoptera: Tenebrionidae). Neotropical Entomology, Vacaria, v.35, n.1, p.75-82, 2006.

ALVES, L.F.A.; ALVES, V. S.; BRESSAN,D.F.; NEVES,P.M. O. J.; ALVES, S. B. Ocorrência de Metarhizium anisopliae (Metsch.) Sorok. em adultos de cascudinho (Alphitobius diaperinus) (Panzer) (Coleoptera: Tenebrionidae) em aviários comerciais em Cascavel, PR. Neotropical Entomology, Vacaria, v.33, n.6, p.793-795, 2004.

ALVES, L. F. A.; ROHDE, C.; ALVES, V. S. Patogenicidade de Steinernema glaseri e $S$. carpocapse (Nematoda: Rhabdita) contra cascudinho, Alphitobius diaperinus (Panzer) (Coleoptera: Tenebrionidae). Neotropical Entomology, Vacaria, v.34, n.1, p.139-141, 2005.

ALVES, S. B.; ALMEIDA, J. E. M.; MOINO JÚNIOR., A.; ALVES, L. F. A. Técnicas de laboratório. In: ALVES, S. B. (Ed.). Controle microbiano de insetos. Piracicaba: FEALQ, 1998. p.637-711.

ALVES, S. B.; LECUONA, R. E. Epizootiologia aplicada ao controle microbiano de insetos. In: ALVES, S. B. (Ed.). Controle microbiano de insetos. Piracicaba: FEALQ, 1998. p.97-169.

AVANCINI, R. M. P.; UETA, M. P. Manure breeding insects (Diptera and Coleoptera) responsible for cestoidosis in caged layer hens. Journal Applied Entomology, Berlin, v.110, n.3, p.307-312, 1990.

AXTELL, R. C.; ARENDS, J. J. Ecology and management of arthropod pests of poultry. Annual Review of Entomology, Stanford, v.35, p.101-126, 1990.

CHERNAKI-LEFFER, A. M. Dinâmica populacional, estimativa da resistência a inseticidas e alternativas de controle para o cascudinho Alphitobius diaperinus (Panzer, 1797) (Coleoptera: Tenbrionidae). 2004. Tese (Doutorado) - Universidade Federal do Paraná, Curitiba.

CHERNAKI-LEFFER, A. M.; BIESDORF, S. M.; ALMEIDA, L. M.; LEFFER, E. V. B.; VIGNE, F. Isolamento de Enterobactérias em Alphitobius diaperinus e na cama 
de aviário no Oeste do estado do Paraná, Brasil. Revista Brasileira de Ciência Avícola, Campinas, v.4, n.3, p.243247, 2002.

CHERNAKI-LEFFER, A. M.; LAZZARI, F. A.; LAZZARI, F. M. N.; ALMEIDA, L. M. Controle do cascudinho. Avicultura Industrial, Itu, v.92, n.1094, p.22-25, out. 2001.

CRAWFORD, P. J.; BROOKS, W. M.; ARENDS, J. J. Efficacy of field-isolated strains of Beauveria bassiana (Moniliales: Moniliaceae) as microbial control agents of the lesser mealworm (Coleoptera: Tenebrioniodae). Journal Economic Entomology, Washington, v.91, n.6, p.1295-1301, 1998.

DESPINS, J. L.; TURNER JR, E. C.; RUSZLER, P. L. Effects of poultry manure moisture and poultry house construction materials on movements of the lesser mealworm, Alphitobius diaperinus (Panzer) (Coleoptera: Tenebrionidae), a structural insect pest in high rise caged layer houses. Poultry Science, Savoy, v.68, n.10, p.1326$1331,1989$.

GARCIA, A.; VAZQUEZ, T.; PEREZ, T.; LUJAN, M. Efectividad de los hongos entomopatógenos Metarhizium anisopliae y Beauveria bassiana en suspensiones conidiales individuales y mezcla de ambos sobre Lissorhoptrus breviostris. Ciencia y Técnica en la Agricultura: Arroz, La Habana, v.13, p.29-38, 1990.

GEDEN, C. J.; ARENDS, J. J.; RUTZ, D. A.; STEINKRAUS, D. C. Laboratory evaluation of Beauveria bassiana (Moniliales: Moniliaceae) against the lesser mealworm, Alphitobius diaperinus (Coleoptera: Tenebrionidae), in poultry litter, soil, and a pupal trap. Biological Control, San Diego, v.13, n.2, p.71-77, 1998.

GEDEN, C. J.; AXTELL, R. C.; BROS, W. M. Susceptibility of the lesser mealworm, Alphitobius diaperinus (Coleoptera: Tenebrionidae) to the entomogenous nematodes Steinernema feltiae, $S$. glaseri (Steinernematidae) and Heterorhabditis heliothidis (Heterorhabditidae). Journal of Entomological Science, Griffin, v.20, n.3, p.331-339, 1985.
INGLIS, G. D.; JONHSON, D. L.; CHENG, K. J.; GOETTEL, M. S. Use of pathogen combinations to overcome the constraints of temperature on entomopathogenic hyphomycetes against grasshoppers. Biological Control, San Diego, v.8, p.143-152, 1997.

KAIA, H. K.; BURLANDO, T. M.; CHOO, H. Y.; THURSTON, G. S. Integration of entomopathogenic nematodes wiht Bacillus thuringiensis or pesticidal soap for control of insect pests. Biological Control, San Diego, v.5, n.3, p.432-441, 1995.

LECUONA, R. E.; ALVES, S. B. Efficiency of Beauveria bassiana (Bals.) Vuill., B. brongniartii (Sacc.) Petch. and granulose virus on Diatraea saccharalis (F.,1794) at different temperatures. Journal Applied Entomology, Berlin, v.105, p.223-228, 1988.

McALLISTER, J. C.; STEELMAN,C. D.; NEWBERRY, L. A.; SKEELES, J. K. Isolation of infectious bursal disease virus from the lesser mealworm, Alphitobius diaperinus (Panzer). Poultry Science, Savoy, v.74, n.1, p.45-49, 1995.

PEREIRA, R. M.; ALVES, S. B.; REIS, P.R. Segurança no emprego de entomopatógenos. In: ALVES, S. B. (Ed.). Controle microbiano de insetos. Piracicaba: FEALQ, 1998. p.171-194.

PEZOWICZ, E. Effects of Steinernematidae and Heterorhabditidae on the lesser mealworm, Alphitobius diaperinus (Coleoptera: Tenebrionidae). IOBC/wprs Bulletin, Darmstadt, v.26, n.1 p.193-195, 2003.

ROHDE, C.; ALVES, L. F. A.; NEVES, P. M. O. J.; ALVES, S. B.; SILVA, E. R. L.; ALMEIDA, J. E. M. Seleção de isolados de Beauveria bassiana (Bals.) Vuill. e Metarhizium anisopliae (Metsch.) Sorok. contra o cascudinho Alphitobius diaperinus (Panzer) (Coleoptera: Tenebrionidae). Neotropical Entomology, Vacaria, v.35, n.2, no prelo, 2006.

STEINKRAUS, D. S.; GEDEN, C. J.; RUTZ, D. A. Susceptibility of lesser mealworm (Coleoptera: Tenebrioniodae) of Beauveria bassiana: effects of host stage formulation, substrate and host passage. Journal of Medical Entomology, Bluffton, v.28, n.3, p.314-321, 1991. 